Of these two methods, the latter is likely to be the less dangerous.

In the event of the acquisition, by this means, of evidence of the presence of a growth, the eyeball should be enucleated immediately. If no such evidence be obtained, the wound may be closed and further operative treatment adopted for the glaucoma, if considered advisable, at a later date.

\title{
REFERENCES
}

1. Neame, H.-Brit. Jl. of Ophthal., Vol. VI, p. 506, 1922.

2. Fuchs. -Text-book of Ophthalmology, p. 787, 1923.

\section{THE COLOURS OF AFTER-IMAGES, FOLLOWING STRONG LIGHT-STIMULI}

\author{
BY
}

\author{
DR. H. WEVE \\ ROTTERDAM
}

\section{Introduction}

THis communication deals with the colours of after-images, following strong light-stimuli, as observed in absolute darkness. We will call these "original" after-images, whilst those modified by fresh light-stimuli will be named "induced" after-images. The observations and theories of former authors (Fechner ${ }^{(1)}$, Plateau, Brücke $^{(2)}$, Helmholtz ${ }^{(3)}$, Séguin, Burch ${ }^{(4)}$ and $\mathrm{McDougall}^{(5)}$ ) will not be discussed here as it is my intention to bring forth in this first communication mere facts, leaving theories for later.

For control of my results the conditions of examination should be identical. The observers must be familiar with physiological work, and their colour sense should be carefully examined. Observations must be carried out uniocularly and in absolute darkness. All influences that could distract the observer's attention should be eliminated. Some exercise is required as the periodical fading of the after-images is disturbing to the beginner. This phenomenon will disappear nearly entirely as a result of sufficient practice.

No pigment-lights were used. In examination with strong. light-sources like direct sunlight and electric arc lamp the excess of ultra-violet rays should be absorbed by the use of colourless glass of sufficient thickness. Much care has to be taken that all after-images of previous light-stimuli have disappeared before starting a new experiment. The observations were registered by speaking in a dictaphone, and a metronome marked the time in 
the same instrument. The duration of the stimulus was regulated by a photographic shutter.

In this way the writer found that the after-images of so-called "white" light of high intensity show a very typical and constant series of colours that is the same for all observers in possession of the same colour sense.

The after-images of spectral radiations of high intensity show other series that are also typical and constant for those radiations and show typical deviations in case of defective colour sense.

A certain intensity of stimulation is wanted for development of the whole series. If this "optimal" degree is once reached, further increase of intensity or duration of stimulation can only influence the duration and brightness of the different colour phases. In case of stimulation of lower intensity or very short duration the series is shortened so that the colours that otherwise were first observed will not now develop. The periodical fading of the after-image and the so-called "halo" will not be considered.

\section{The after-image of so-called white light}

Let us begin by describing what is observed after staring at the sun for a few seconds. Immediately after the termination of this stimulus we often have a feeling of confusion, called by McDougall "dazzling period." Then we suddenly observe a disc of clear light blue colour. It is not the blue of the Italian sky, but the less saturated luminous blue of a Dutch sky in bright sunlight. After a short time this blue is replaced by an equally clear golden yellow, generally of short duration, and this passes via a yellowish green into a pure spectral green of rather full saturation. This in its turn is, after some time, replaced by an unsaturated crimson, approaching purple rather than spectral red. This red is so constant and characteristic that whenever observing it as a primary light perception I for long have been in the habit of calling it "after-image red." This phase again lasts longer than the preceding green phase; finally, it is replaced by a deep bluishgreen.

Under favourable conditions we observe this bluish-green with a clearness which shows that it differs in no respect from the other colour phases. The fact, however, that in many cases the afterimage has in this stage decreased so much in intensity, that the colour can hardly be identified and the surrounding "halo" seems brighter than the after-image itself, has induced former observers to indicate this phase as a "negative" one.

Here I wish to state as my opinion that the words positive and negative should not be used in the description of the original afterimage as this would cause confusion with the entirely different 
sense of the words in the description of secondary after-images. Moreover, they include a presumed theoretical explanation of the facts observed.

After an observation of several minutes the after-image will disappear altogether, but a very weak light-stimulus will show, that the part of the retina formerly struck by the sunlight has by no means returned to its primary state. There still exists a relative partial scotoma, and, moreover, new after-images of the sun can be formed. These are colourless if the secondary stimulus is weak. The latter phenomenon will not be further discussed here.

The case here described is an ideal one as it is supposed that the fixation of the sunlight was perfect. In most cases this fixation will be imperfect and in consequence the centre of the image will be much more strongly stimulated than the periphery.

As the after-images show more colour phases in proportion to the intensity of the light action the centre will generally show another colour than the periphery, and even three or more colours can appear in the same after-image so that the centre is surrounded by two or more rings of different colours. Imperfect fixation of the source of light may also account for the fact that the colour changes seem to proceed from the periphery to the centre.

If the after-image passes from one colour to another, which is not complementary, as for instance from yellow to green, this change mostly occurs via the mixed colour, in this case yellowgreen. If, however, the change takes place from a colour to its complement, for-instance from red to green, this does not occur via the mixed colour yellow, but the change is a sudden one recalling the way in which moisture fades from a hot surface (Fechner), or in other cases there is for one moment a mosaic work of both colours.

The colours themselves show alterations in their saturation, especially the carmine red is ofen unsaturated, although it may now and then reach a high degree of saturation so that one might agree with $\mathrm{McD}$ ougall that perhaps there is no other method that. enables us to obtain more saturated colour perceptions, but generally the author's red is not so saturated as McDougall's seems to be. Apart from the fluctuations of saturation the afterimage as a whole diminishes in brightness in proportion to the time it lasts.

As said before, the colours succeed in invariable order. If the light stimulus is weaker, the series starts with yellow-green or green or even with red, and in this case only these colours will be observed that follow in the invariable order : blue, yellow, green, red, bluish-green. As a consequence the colour that is first observed also disappears first. The author never observed in the after-image pronounced spectral red, orange, and spectral violet. 


\section{On the after-images of strong spectral radiations}

As a spectroscope allowing intense stimulation was not at the author's disposal, light-filters had to be used for the examination of the after-images of spectral radiations. The Wratten monochromatic filters (Wratten, Wainwright, Ltd., Kodak House, London) were used in combination with direct sunlight, electric arc and quartz mercury lamp.

Here follows the result of repeated spectroscopical examination of the filters :

\begin{tabular}{|c|c|c|c|}
\hline $\begin{array}{l}\text { No. in } \\
\text { Catalogue }\end{array}$ & $\begin{array}{l}\text { Colour in } \\
\text { daylight }\end{array}$ & $\begin{array}{l}\text { Wave } \\
\text { length in } \mu \mu\end{array}$ & $\begin{array}{l}\text { Colour in spectroscope, } \\
\text { using sunlight }\end{array}$ \\
\hline $\begin{array}{l}70 \mathrm{~A} \\
74\end{array}$ & $\begin{array}{l}\text { Red } \\
\text { Green }\end{array}$ & $\begin{array}{l}650-720 \\
515-565\end{array}$ & Red \\
\hline 76 & Blue & $430-475$ & Blue and violet \\
\hline 73 & Olive-green & $\begin{array}{c}550-620 \\
\text { (trace } 670-740)\end{array}$ & $\begin{array}{l}\text { Yellow, yellow-green, trace } \\
\text { green and trace orange-red }\end{array}$ \\
\hline G & Yellow & $520-700$ & $\begin{array}{l}\text { Red, orange, yellow, yellow- } \\
\text { green up to } 520 \mu \mu\end{array}$ \\
\hline
\end{tabular}

The spectrum of our quartz mercury lamp showed the following lines: Yellow $577 \mu \mu$, green $54 \tau \mu \mu$, blue $436 \mu \mu$, violet $405 \mu \mu$. Combination of this lamp with filter 76 gives pure blue $436 \mu \mu$; combination of this lamp with filter $G$ and filter 73 gives pure yellow 5 ז $i \mu \mu$.

Thus the filters $70 \mathrm{~A}$ and $\pi 4$ in combination with arc light or sunlight provided us with spectral red and spectral green of high intensity, and the use of the filter 76 and the combined filters G. and 73 with the quartz mercury lamp secured us a pure spectral blue and yellow. The duration of exposure varied from 1 to 20 seconds. We found here just as in the above-mentioned experiments with so-called "white" light, that the full series of afterimage colours, characteristic for each spectral radiation, develops by using stimulations of moderate intensity and duration. Stronger stimulation can only influence brightness and duration of the afterimage. The best results were obtained with exposure lasting from 5 to 10 seconds, using direct sunlight and the above-mentioned filters. Controlling observations were made by excluding ultraviolet rays by adding a sheet of heavy flint glass (Schott, Jena). This had no influence on the results obtained, but is advisable as a protection of the fovea. Using the quartz mercury lamp care should be taken to exclude, with the help of screens, the light 
radiated by the glowing quartz. The principal results of our observations follow here :

1. Using sunlight :

Spectral red gives the following series of after-inage colours.

Spectral green.

Carmine red.

Deep bluish-green.

Spectral green gives :

Yellow.

Yellow-green.

Green.

Bluish-green (sometimes with blue mosaic). Carmine red.

Spectral blue plus violet gives :

Spectral blue.

Violet purple.

2. Using arc lamp :

Spectral red gives exactly the same colours as by using sunlight.

Spectral green gives :

Exclusively green.

(Here yellow as well as red observed in using direct sunlight failed.)

Spectral blue plus violet gives exactly the same colours as by using sunlight.

3. Using quartz mercury lamp :

Spectral yellow gives:

Bluish-white (fails often).

Yellow or yellow-green, quickly passing to green.

Carmine red.

Deep bluish-green.

Spectral blue gives :

Light blue.

Unsaturated carmine red.

Dirty yellow-green in which later on the green slightly predominates.

With the help of a collection of pastel colours we have tried to fix the most characteristic colour phases of the after-image. (Plate I.) As the carmine red is the only colour we meet with in all after-images we arranged the colours in such a way that this red is found in the same vertical row. 


\begin{tabular}{|c|c|c|c|c|c|c|}
\hline $\begin{array}{c}\text { Primary } \\
\text { light }\end{array}$ & & \multicolumn{5}{|c|}{ After-image } \\
\hline White & ... & Blue & Yellow & Green & Carmine & Bluish- \\
\hline Yellow & ... & $\begin{array}{l}\text { Bluish- } \\
\text { white }\end{array}$ & Yellow & Green & $\begin{array}{l}\text { Carmine } \\
\text { red }\end{array}$ & $\begin{array}{l}\text { Bluish- } \\
\text { green }\end{array}$ \\
\hline Blue & $\ldots$ & Blue & - & Blu & $\begin{array}{l}\text { Carmine } \\
\text { red } \\
\text { green }\end{array}$ & $\begin{array}{l}\text { Yellow- } \\
\text { green }\end{array}$ \\
\hline Green & $\ldots$ & - & Yellow & & $\begin{array}{c}\text { Carmine } \\
\text { red }\end{array}$ & - \\
\hline Red & $\ldots$ & - & - & Green & $\begin{array}{l}\text { Carmine } \\
\text { red }\end{array}$ & $\begin{array}{l}\text { Bluish- } \\
\text { green }\end{array}$ \\
\hline
\end{tabular}

In this scheme we have limited ourselves to the reproduction of the most constant and characteristic colours. The change in saturation as well as the appearance of colour mixtures gives rise to richer variations than are reproduced here. The reproduction does not give in any way an exact representation of the course of the after-image process. The dark intervals which separate the colours are entirely arbitrary and should not be identified with the phases of darkness that often, and more or less systematically, interrupt the course of the process. Our registrations with help of the dictaphone prove that there is not the slightest connection between these periodical obscurations and the different colour phases. Also the duration of the different colour phases is not exactly reproduced. The author merely wanted to indicate that generally the first phases are the shortest and that generally they last the longer the later they occur in the series.

Nevertheless this scheme allows us to point out some remarkable facts. We have mentioned already that the characteristic carmine "after-image red" is the only colour that returns in all the experiments. Secondly, it strikes us that with few exceptions the succession of the colours is in all cases the same as it is for white light. Some phases may be omitted-the succession is the same. The only exception seems to be that in the after-image of green the green takes a bluish hue before changing into red whilst in the other observations a bluish-green followed this same red, but this fact cannot entirely suppress the suggestion that the after-image colours of the different spectral colours examined are parts of the whole cycle developed by white light. It seems to be a general rule that spectral radiations cannot develop any after-image colour that is not to be found in the cycle of the so-called "white" light (apart from differences in saturation and hue). 
If we consider the different radiations more closely still, other remarkable facts will strike us. First the great analogy of the after-image colours of white and pure spectral yellow is astonishing. In some of my observations a first phase of unsaturated blue was noticed; in others I was inclined to call this phase colourless, whilst in a third series of observations this phase seemed to fail. In all further respects the identity of the after-image colours of yellow of wave length $577 \mu \mu$ with those of sunlight and arc light is complete. This seems to indicate a very high degree of identity between the biochemical processes caused in the retina by such different stimuli.

The spectral blue of wave length $436 \mu \mu$ causes nearly the same after-image colours as the blue combined with violet $(430-475 \mu \mu)$ and both differ widely from the after-images of white light, consisting nearly exclusively of a blue and a carmine-red phase. In contrast with the well-known facts, stated with induced after-images, the so-called complementary phase is missed in the original afterimage of blue. The dirty yellowish-green I observed sometimes as a last faint phase of the series can hardly be considered as such.

The spectral green $(515-565 \mu \mu)$ in its turn gives, much like the spectral yellow, nearly all the after-image colours of white, but in a somewhat modified order. Only the blue phase is missed entirely.

The spectral red on the contrary gives only the last three phases of the after-images of white. It is the only colour examined, in whose after-image the so-called "complementary" colour predominates. We know that a certain mixture of thallium-green and lithium-red gives the impression of sodium-yellow. It is a striking fact that addition of the after-image colours of spectral red and green does not form the cycle of yellow. The blue phase is still missing, as well in the after-image of red as of green. Only by adding a third colour--blue or yellow-the whole cycle as observed in white or yellow light is obtained.

If we agree with Götz(6), who describes the after-images as "selbständige, auf selbständigen physiologischen Prozessen (Nachwirkungen der photochemische Folgen des Lichteindrückes) beruhende psychische Erscheinungen" then the study of "farbiges Abklingen" teaches us that the biochemical processes of the retina caused by pure spectral radiations are much more complicated than some theories of colour vision might suggest. If red, for instance, is the sole colour examined, it presents in its after-image chiefly. "complementary" colours as Hering's theory would demand. For blue and yellow, however, a "complementary" phase in the afterimage fails completely or practically so, whilst the appearance of yellow in the after-image of green remains unexplained by Hering's hivpothesis. Both Helmholtz and Hering were well aware that the 
study of the colours of the after-images was in contradiction with their theories.

Hering $(7)$ wrote in 1878 "Von der Anwendung einer irgend starken Beleuchtung muss bei diesem wie bei allen folgenden Versuchen ganz besonders gewarnt werden, weil man dadurch nicht blos seine Augen angreift, sondern, was das eigentlich Wesentliche ist, ganz andere und sozusagen unreine Resultate bekommt."

Helmholtz ${ }^{(3)}$ writes : "Die sehr zusammengesetzten Erscheinungen des farbigen Abklingens starker oder anhaltender Lichteindrücke vollständig auf ein einfaches Schema zurückzuführen, möchte freilich vor der Hand noch schwer sein und allerlei willkürliche Annahmen nothwendig machen."

With due respect to two giants of science like von Helmholtz and Hering the author ventures to give as his opinion that the study of the original after-images of strong light-stimuli might be of much use for the study of light perception and even that the induced after-images can only be understood after studying the original after-images.

This is a first attempt, and I am well aware that it is very incomplete. Though we succeeded in experimenting with spectral red, green, blue, and yellow of high purity and brightness we could not extend our observations to spectral orange, yellow-green, bluegreen, and violet. The reactions caused by these radiations are, however, of special interest, and our next task should be to find out whether the after-images of orange are intermediate between those of red and yellow and whether those of yellow-green and blue-green are intermediate between the after-images of the separated colours.

If a spectrum of high luminosity were at our disposal it would be very interesting to seek the "curve" of after-image colours throughout the spectrum for radiations of "optimal" brightness. As "optimal" brightness I regard the lowest brightness that produces clearly the whole series of after-image colours which are characteristic for a distinct radiation. Further progress of our knowledge is to be expected from the study of the after-images in different parts of the retina. It is to be understood that the above observations refer only to central perception. In this communication we will also give some account of the after-images in cases of defective colour sense.

IV. On the colours of after-images, following strong lightstimuli as observed by Daltonists and anomalous trichromats

It seemed to me of both theoretical and practical importance to study the after-images of Daltonists and anomalous trichromats. For this purpose I had the assistance of two colleagues-ophthal- 
mologists-Drs. M. and S., to whom I am greatly obliged as it is of much importance to experiment with good observers, therefore I will give their results in extenso. The colour sense of both was thoroughly examined not only with the pseudo-isochromatic figures of Stilling and the "Tafeln" of Nagel, but also with Nagel's anomaloscope and even the spectral curve of brightness was determined for one of them (Dr. M.). For comparison with later observers I will give the results of the examination with the anomaloscope for both of them.

Dichromats, or so-called Daltonists, perceive in their afterimages, independent of the kind of inducing radiation, either no colour at all or they call it yellow or bluish, but they never seem to observe alternative changes of colour in the same after-image. They never spontaneously mention red or green; if asked for it they now and then call some phase reluctantly "reddish." Here follow the results obtained by Dr. M., who is a pronounced protanopic Daltonist, though he himself protests against the idea that he would not be able to perceive "red and green."

Examination with Nagel's Anomaloscope. If the left screw indicates pure green, then the right screw is turned to 57 . If the left screw gives pure red, then the right is turned to 3 . The Rayleigh-equation is adjusted almost in the same way as by normal observers. (Yellow 22 is red-green 51.)

\section{After-Images.}

White light (electric arc light) After-image: "White" or in other experiments "blue or bluish" (with yellow halo).

Spectral Red (Filter 70) : Colour of After-image undefinable; of very short duration.

Spectral Red and Orange (Filter 71) After-image : A dull blue.

Spectral Blue and Violet (Filter 76) After-image: "White"; in other experiments faintly blue or faintly yellow.

Spectral Green (Filter 74) After-image very faintly yellow hue, later on pure white.

Spectral Yellow (Filter G and 73 with mercury lamp) After-image "bluish."

Analogous results were given by other Daltonists without exception.

The anamalous trichromats in contrast with the Daltonists perceive without any difficulty a much richer series of colours, as is illustrated by the results obtained by Dr. S., who is an extreme deuteranomal. Dr. S. himself did not admit that his sense of colour vision was defective though his family had often told him so. By examination with Nagel's Anomaloscope-

Experiment 1.-A pure red is presented; the yellow has to be changed into equality. 
Right eye : One moment adjusted yellow 12 , immediately afterwards rejected.

Left eye : Rejected "it must be about yellow 15."

Experiment 2.-Adjusted yellow 12.5; the red-green mixture must be changed until equality is reached.

Right eye : Equality red-green 68 .

Left eye : Equality red-green 68.

Experiment 3.- Red-green adjusted to 49 (average of deuteranomals). Brightness of yellow must be changed into equality.

Right eye : Equality, yellow 20 to 18.

Left eye : Equality, yellow 1\%.

Experiment 4.-Red-green adjusted to 70 (average of protanomals). The yellow has to be changed into equality.

Right eye : Impossible to reach equality.

Left eye : Impossible to reach equality, seeks about 11.5.

Experiment 5.-Pure green is adjusted. Yellow has to be varied into equality.

Right eye : Green is equal to yellow 32 .

Left eye : Green is equal to yellow 31 .

From this and other examinations it is clear that Dr. S. is an extreme deuteranomal.

For Dr. S. we found the following after-image colours in repeated observations :

"White" light (Sun) : Yellow-green, red, dark blue.

"White" light (Auer lamp) : Yellow, green, red, blue-green, blue.

Spectral Yellow $(577 \mu \mu)$ : Yellow-green, green, "tile" red, blue.

Spectral Blue $(436 \mu \mu)$ : Blue (sky blue), green-yellow, orangebrown into rust red.

Spectral Green (515-565 $\mu \mu)$ : Yellow, pink (also called, unsaturated red and orange red), green, or blue-green or blue.

Spectral Red (650-720 $\mu \mu)$ : Yellow (also called orange), red, green (also called green-blue, and dark blue).

In all these observations the author could compare his own afterimages directly with those of Dr. S. They did not differ in any essential respect from those described before.

Though the extreme deuteranomal described his after-image colours with much certainty it was clear from comparison of different observations that he had some difficulty in determining the hue of obviously identical phases. So in one series he called blue-green what in another was called blue or blue-green. In one series he called "orange-brown," what in another was called "rust red," and so"on. I will not discuss here to what degree the differences between the normal and the anomalous trichromat are only apparent, because of the fact that his nomenclature is different, 
but comparison of the results here obtained with those of the dichromat and the normal shows evidently that there is an enormous difference between the dichromat and the anomalous trichromat on the one hand and a close resemblance between the after-images of the anomalous trichromats and the normals on the other hand.

This resemblance is best illustrated by comparing Plates I and II. In Plate II, I recorded in colours the description of Dr. S., just as I myself understood his nomenclature and then for comparison added the after-image colours of the dichromat.

From this illustration we learn the following : First we see that deuteranomals just as normals perceive in the after-images of spectral radiations only such colours as are found in the afterimage of the so-called "white" light, being his only fundamental colours, yellow, blue, red, and green. Then we must draw attention to the fact that just as in normal trichromats, the afterimages of "white" and yellow are nearly identical. They only differ from those of normals by the absence of the first phase, the sky-blue. (There are some other differences of less importance as the use of the name "tile-red" in the carmine-red phase of the normal.)

The after-images of blue (Dr. S.) show also the remarkable fact that this is the only radiation examined where the first phase of the after-image is completely identical with the primary perception. For the after-images of red and green it is highly characteristic for Dr. S. that they are practically identical. This well coincides with the fact that they are "interchangeable" colours.

Up till now I am not able to foretell whether it will be possible to distinguish by the study of the after-image colours the different forms of anomalous trichromats, as it is essential to examine trained observers, who were not at my disposal. As far, however, as Daltonists and anomalous trichromats are concerned there is perhaps no method that enables us to distinguish those categories with such simple means. An incandescent lamp, an electric bulb, a little bit of sunshine allow the differentiation.

As far as I survey the literature on this subject only Guttman ${ }^{(8)}$ has paid attention to the after-images of the colour blind. According to him the after-images of anomalous trichromats, if examined with spectral radiations, are in agreement with those of dichromats; if examined with pigment-colours on the contrary they would agree with normal trichromats. The intensity of the radiations used by Guttman is, however, much lower, and his results, therefore, are not directly comparable with those above described.

Once more the author wishes to state that this first communication does not exhaust in any way the subject, but he will be rewarded 
if the results obtained awaken some interest in a method of investigation of the problem of light and colour perception that, in his opinion, has been too long neglected.

\section{LITERATURE (exclusively as far as quoted above)}

1. Fechner.-Uber die subject. Nachbilder und Nebenbilder. Ann. der Physik und Chemie, Bd. 44, 1838 ; Bd. 50, 1840.

2. Brïicke, E.-Untersuchungen über subjective Farben. Ann.der Physik und Chernie. Bd. 84, 1851.

3. Helmholtz v.-Physiol. Optik. (zweite Aufl.), 1896.

4. Burch, G. J.-Proc. of the Roy. Soc. of London, Vol LXIII, 1898.

5. McDougall, W.-Some New Observations in Support of Thomas Young's Theory of Light and Colour Vision. Mind, Vol. X, 1901.

6. Götz, Martius.-Das Gesetz der Helligkeitswerte der negat. Nachbilder. Beiträge zur Phys. und Philos., 1896.

7. Hering.-Zur Lehre vom Lichtsinne. Wiener Akadamie, 1878.

8. Guttman.-Zeitschr.f. Sinnesphysiol., XIII, 1907 ; idem. LVII, 1910.

\section{ANNOTATION}

\section{Ophthalmic Folk-lore}

In considering ophthalmic folk-lore we can divide the subject into matters pertaining to the evil-eye and ocular remedies. The first of these is pure superstition, a survival of the belief in witchcraft, which if not yet entirely eradicated from the more remote parts of the country, must, in these enlightened times, be very rare indeed. We do not propose to say any more about the evil-eye, but to confine ourselves to the primitive ophthalmic remedies of the countryside.

The popular superstition that rain water caught on Ascension Day is good for sore eyes can have, we think, no foundation in fact. Rain water caught on any other day in the year would be just as cleansing, and as an eye-wash could do but little harm. The various Holy wells, the waters of which are popularly supposed to be good for inflamed eyes, owe their success apart from the psychological effect, probably to the salts dissolved in the water and to the general cleansing effect of the water. It is difficult to see any scientific basis in the treatment of styes by rubbing them with a ring, whether the ring be made of gold or of iron from the nails of coffins; but for all that, it was a popular remedy among country folk. Probably there is more to be said for the practice of applying half a rotten apple to a stye; this would act like a bread poultice, and would probably be as septic and occasionally as efficacious as that old-fashioned remedy.

Flowers and plants, of course, had and still have a large part to play in the treatment of eye diseases. Eyebright, fennel, rue, and 